\title{
Analysis of Nonlinear Signal Interference to Optimize the Coherent Optical Transmission System
}

\author{
Abdul Gafur ${ }^{1}$ \\ ${ }^{I}$ Department of Electronic and Telecommunications Engineering, International Islamic University Chittagong, \\ Bangladesh
}

\begin{abstract}
In this paper we analyze the power of Nonlinear Signal Inference $\left(p_{N L S I}\right)$ and optimize the coherent optical transmission system (COTS) based on PM-16QAM higher modulation format for different baud rates considering commercially available silica fiber (SF). Theoretically, this work follows up four Gaussian Noise $(G N)$ models depending on multiple identical spans, non-Nyquist WDM system, non-identical spans and multichannels to confirm the better accuracy of these models. The most fitted model is then used to optimize the COTS achieved by analyzing the Amplified Spontaneous Emission noise power $\left(P_{A S E}\right)$ to determine the optimum Optical Signal to Noise Ratio (OSNR). Matlab R2011b simulation tool is run here to generate the OSNR and Bit Error Rate (BER) performance curves for the COTS. The OSNR has been simulated considering input transmitting power per span, span length, dispersion and fiber loss coefficient. Results show that, the OSNR penalty is around $3 d B$ and $6 d B$ when line rate is multiplied with the factor of $2 x$ bit rate, $4 x$ bit rate respectively for same modulation and demodulation formats in the COTS.
\end{abstract}

Keywords: OSNR, PM-16QAM, GN, SF, BER

\section{Introduction}

Usually laser coherence is utilized in coherent optical transmission system. Here optical signal carrying capacity and transmission rate are the key factors to upgrade in the existing optical network. On the other hand, capacity depends on higher line rate and spectral efficiency of the channels [1]. The desired optical link performance based on higher line rate and narrower channel spacing for each non-identical channel in wavelength division multiplexing technique can be achieved [2]. Similarly, optical link set up and processing takes long time for submarine network where terrestrial network is easier, not more difficult but it is little bit challenging to improve and optimize the capacity of the network [3].

Thus, to achieve the significant OSNR, higher Baud rate and more spectral efficient modulation techniques are required to enhance the performance of the COTS. For this, higher channel power, lower fiber loss coefficient and lower nonlinearity factors are expected for higher OSNR [1]. Like submarine link, for higher line rate, COTS plays an important job for lower cost information transmission because of DWDM and EDFA in the transmitter and the chain of the link respectively. Consequently, optimization is an important issue to upgrade and minimize the higher cost of the existing optical network considering higher modulation formats [4]. The performance of COTS is also obtained through the improvement of the nonlinear optical signal propagation.In this regard, we have considered four GN models on multiple identical spans, non-Nyquist WDM system, non identical spans and multi-channels.

To get the best performance of COTS, the power of NLSI is the dominating factor which occurs for non-identical channel propagation in the link. That's why we follow the algorithm of scheduling used for nonlinear propagation where linear routing and wavelength choice finding are the great problems [5]. As a result, accuracy and simple simulation process are required to obtain the best performance of the link. In this case, non-linear Schrodinger equation complies with these factors. For this situation, it is very hard to find out the power spectral density of NLSI and simulation process takes longer time. Moreover, the commercial optical simulator software is expensive and simulation running output takes longer time [6]. Consequently, GN model is the way and method to determine the power of nonlinear signal interference ( $\left.p_{N L S I}\right)$ [7-9]. In GN model, we control the total number of spans causing variation to the link length randomly [10].

In this way, we set the input transmitting power $\left(P_{T X}\right), p_{N L S I}$ and $P_{A S E}$ for each span to obtain the optimum OSNR performance for the COTS. After each span we confirm the OSNR which is calculated after total number of spans.

For span length, we take SF commercial fibers [11] - [12] for 50 numbers of spans.

It is an important issue to consider the values of OSNR for the receiver section. Firstly, the receiver part cannot identify the signal for low values of OSNR. Secondly, to reach the maximum point parameters, wavelength goes through generation and regeneration in the link. Thirdly, OSNR values estimate the performance of the system and make an assurance of error free transmission in the link. Fourthly, BER is of 
crucial value and quality of propagation of the optical signal which is dependent on OSNR values. Considering all these factors, it can be said that OSNR is an important parameter and it depends on number of optical links, topology of the network, symbol rate of the higher modulation formats and the target of lower BER to design the optical network efficiently [13].The optical link model used for the simulation is shown in Fig. 1. The total number of channels in the transmitter section is divided into odd and even number of channels to implement polarization multiplexing. The number of channels in the WDM comb is 27 channels with the $14^{\text {th }}$ channel considered as the Centre.

Every channel has a channel bandwidth, channel power and line rate respectively. The modulated optical signal goes through the optical filter [14] then the combiner combines the channels. The specification data for SF are shown in Table 1. The EDFA is connected after a span of $100-\mathrm{km}$. A noise figure of $5 \mathrm{~dB}$ compensates the link loss depending on the fiber loss coefficient and span length.The $\mathrm{p}_{\mathrm{NLSI}}$ is determined at the input of the EDFA and the $\mathrm{P}_{\mathrm{ASE}}$ is observed at the output of the EDFA [15] in the optical link of the COTS as shown in Fig. 1 [9].In this condition 27 WDM comb are considered where $193.4145 \mathrm{THz}$ is the center channel frequency within the range from $192.7645 \mathrm{THz}$ to $194.0645 \mathrm{THz}$. These channel frequencies create odd and even number of channels with $0.05 \mathrm{THz}$ spacing. The simulation is performed for $5000 \mathrm{~km}$ silica fiber link distance considering $128 \mathrm{~Gb} / \mathrm{s}$ and $256 \mathrm{~Gb} / \mathrm{s}$. We analyze the GN models for different modes and conditions to predict the accuracy among the models. The power spectrum of the ASE noise is considered to obtain the optimum OSNR for the COTS.

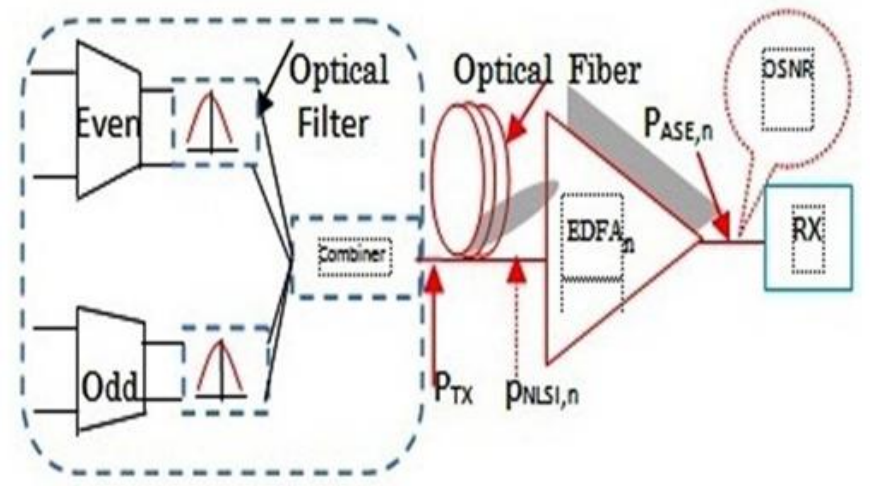

Fig. 1: Model of optical link.

\section{Analysis of nonlinear signal interference (NLSI)}

In this work we follow four Gaussian non-linear (GN) models to determine the accuracy and convergences of the models in optical coherent transmission. Then we choose very close and tight fit convergence of GN model to determine the optimum ONSR for different line rate $\left(R_{s}\right)$ in the COTS.

The power $p_{N L S I}$ depends on Gaussian nonlinear $(\mathrm{GN})$ signal spectrum considering an optical noise bandwidth of $12.5 \mathrm{GHz}$. The expression for $p_{N L S I}$ in the case of multichannels is presented below [19]

$p_{N L S I^{1}}=\frac{8}{27} N_{s} \gamma^{2} L_{e f f} P_{C h}^{3} \frac{\log \left(\pi^{2}\left|\beta_{2}\right| L_{e f f} N_{C h}^{2} R_{s}^{2}\right)}{\pi\left|\beta_{2}\right| R_{s}^{3}} B_{n}$

In the above expression, $N_{s}, \gamma, L_{\text {eff }}, P_{C h}, \beta_{2}, N_{C h}, R_{s}$ and $B_{n}$ are the number of span, non-linearity coefficient, effective length, channel power, dispersion parameter of fiber, number of channels, line rate of the channel and optical noise bandwidth of COTS respectively.

We also follow the GN model for non identical span and mathematical expression are shown below to calculate the $p_{N L S I}:[10,20]$

$$
\begin{aligned}
p_{N L S I^{2}}= & \frac{16}{27} \cdot B_{n} \sum_{n_{s}=1}^{N_{s}} \gamma_{n_{s}}^{2} L_{e f f, n_{s}}^{2} \\
& \cdot \prod_{n_{s}^{\prime}=1}^{n_{s}-1} g_{n_{s}^{\prime}}^{3} e^{-6 \alpha_{n_{s}^{\prime}} L_{s, n_{s}^{\prime}}} \cdot \prod_{n_{s}^{\prime}=n_{s}}^{N_{s}} g_{n_{s}^{\prime}} e^{-2 \alpha_{n_{s}^{\prime}} L_{s, n_{s}^{\prime}}} \\
& \cdot \sum_{n=1}^{N_{c h}} G_{c h, n} G_{c h, n} G_{c h, i} \cdot\left(2-\delta_{n, i}\right) \Psi_{n, i, n_{s}}
\end{aligned}
$$


The effective length is calculated for using the following equation [15]:

$L_{\text {eff }}=\left[1-e^{-\left(\alpha . L_{s}\right)}\right] / 2 \alpha$

Where $\alpha$ is the fiber loss coefficient and $L_{s}$ is the span length of the COTS.

The power spectral density for $\mathrm{n}^{\text {th }}$ and $\mathrm{i}^{\text {th }}$ channels are given in [17] is used in the model as below,

$G_{c h, n}=\frac{P_{c h, n}}{R_{s}}$

$G_{c h, i}=\frac{P_{c h, i}}{R_{s}}$

Where for $n^{t h}$ and $i^{t h}$ channels, the channel power is $P_{c h, n}$ and $P_{c h, i}$ respectively. The symbol $\delta_{n i}$ is used to maintain the center frequency for the WDM comb based on 0 and 1 condition when $n=i$ and $n \neq i$ respectively.

When $n=i$ and the symbols $\Psi_{n, i, n_{s}}$ and $\Psi_{i, i, n_{s}}$ are used in model to select the strategy of the channel [10], [20]

$$
\begin{aligned}
& \Psi_{n, i, n_{s}}= \frac{\operatorname{asinh}\left(\pi^{2}\left(2 \alpha_{n_{s}}\right)^{-1}\left|\beta_{2, n_{s}}\right|\left[f_{c h, n}-f_{c h, i}+B_{c h, n} / 2\right] B_{c h, i}\right)}{4 \pi\left(2 \alpha_{n_{s}}\right)^{-1}\left|\beta_{2, n_{s}}\right|} \\
&-\frac{\operatorname{asinh}\left(\pi^{2}\left(2 \alpha_{n_{s}}\right)^{-1}\left|\beta_{2, n_{s}}\right|\left[f_{c h, n}-f_{c h, i}-B_{c h, n} / 2\right] B_{c h, i}\right)}{4 \pi\left(2 \alpha_{n_{s}}\right)^{-1}\left|\beta_{2, n_{s}}\right|} \\
& \Psi_{i, i, n_{s}}=\frac{\operatorname{asinh}\left(\frac{\pi^{2}}{2}\left|\beta_{2, n_{s}}\right|\left[2 \alpha_{n_{s}}\right]^{-1} B_{c h, i}^{2}\right)}{2 \pi\left|\beta_{2, n_{s}}\right|\left[2 \alpha_{n_{s}}\right]^{-1}}
\end{aligned}
$$

Where $\beta_{2}$ and $B_{c h}$ are the second order fiber dispersion parameter and $-3 \mathrm{~dB}$ channel bandwidth respectively. For the $i^{\text {th }}$ channel, the center channel is denoted as $f_{c h, i}$ in the comb.

For the model accuracy, the $p_{N L S I}$ expression is for the case of Non-Nyquist and presented below [5]

$$
\begin{aligned}
p_{N L S I^{3}}= & \left(\frac{8}{27}\right) \cdot B_{n} \cdot \gamma^{2} \cdot \frac{L_{e f f}^{2} G_{W D M}^{3}}{\pi\left|\beta_{2}\right| L_{e f f, a}} \\
& . \operatorname{asinh}\left(\frac{1}{2} \pi^{2}\left|\beta_{2}\right| L_{e f f, a} R_{s}^{2}\left[N_{c h}^{2}\right]^{\frac{R_{s}}{\Delta f}}\right)
\end{aligned}
$$

where $L_{e f f, a}$ and $G_{W D M}$ are the asymptotic effective length and PSD of the transmission in the super channel of comb. In the model, asymptotic effective length is used in the following way:

$$
L_{e f f, a}=\frac{1}{\alpha}
$$

The $p_{N L S I}$ analysis is for the case of multiple identical spans model [9] is shown below

$$
\begin{aligned}
p_{N L I}{ }^{4} & =\frac{64}{27} B_{n} \gamma^{2} \int_{-\infty}^{\infty} \int_{-\infty}^{\infty} G_{T x}\left(f_{1}\right) G_{T x}\left(f_{2}\right) G_{T x}\left(f_{1}+f_{2}-f\right) \\
& \left|\frac{1-e^{-2 \alpha L_{s}} e^{j 4 \pi^{2}\left|\beta_{2}\right| L_{s}\left(f_{1}-f\right)\left(f_{2}-f\right)}}{2 \alpha-j 4 \pi^{2}\left|\beta_{2}\right|\left(f_{1}-f\right)\left(f_{2}-f\right)}\right|^{2} \\
& \cdot \frac{\sin ^{2}\left(2 \pi^{2} N_{s}\left(f_{1}-f\right)\left(f_{2}-f\right)\left|\beta_{2}\right| L_{s}\right)}{\sin ^{2}\left(2 \pi^{2}\left(f_{1}-f\right)\left(f_{2}-f\right)\left|\beta_{2}\right| L_{s}\right)} d f_{2} d f_{1}
\end{aligned}
$$


In Eq. (10), $G_{T x}$ is the PSD which depends on channel power and line rate. The frequencies $\left(f_{1}+f_{2}-f\right)$ for four wave mixing (FWM) are the elements frequency of $f[16]$.

\section{OSNR And Bit Error Rate (BER) Performance Evaluation}

Based on analytical analysis of nonlinear signal interference, the numerical results are simulated in Fig.2 (a) and Fig.2 (b) considering four GN models using Matlab R2011b tool. These results confirm the convergence and accuracy among the models.

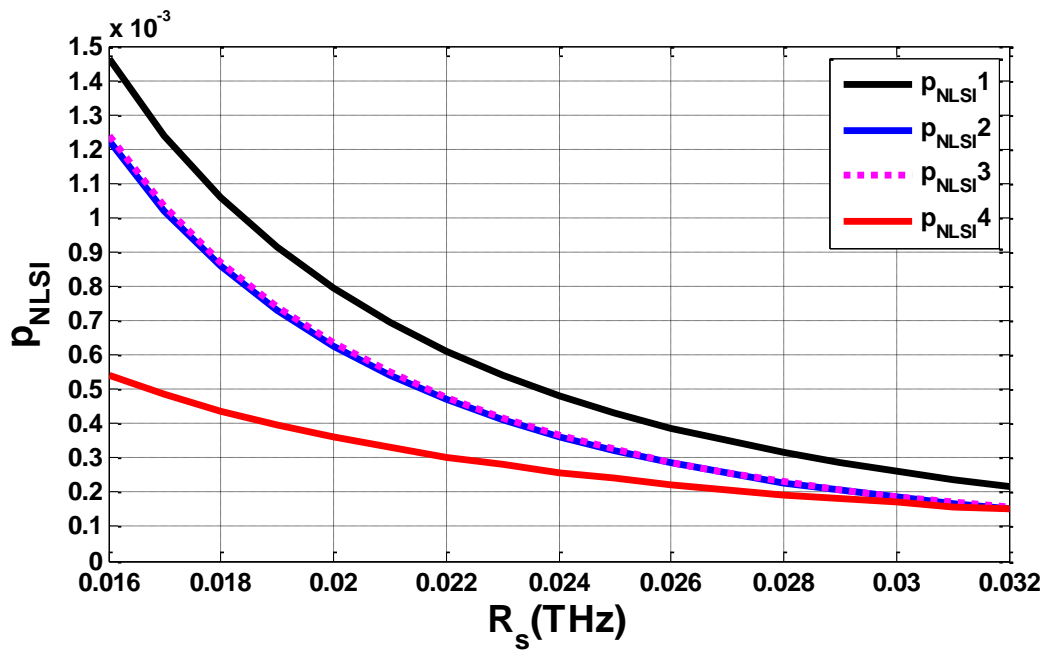

Fig. 2 (a): Non linear signal interference for four GN models considering power of nonlinear signal interference $\left(p_{N L S I}\right)$ vs. line rate $\left(\mathrm{R}_{\mathrm{s}}\right)$ with $\mathrm{SF}$.

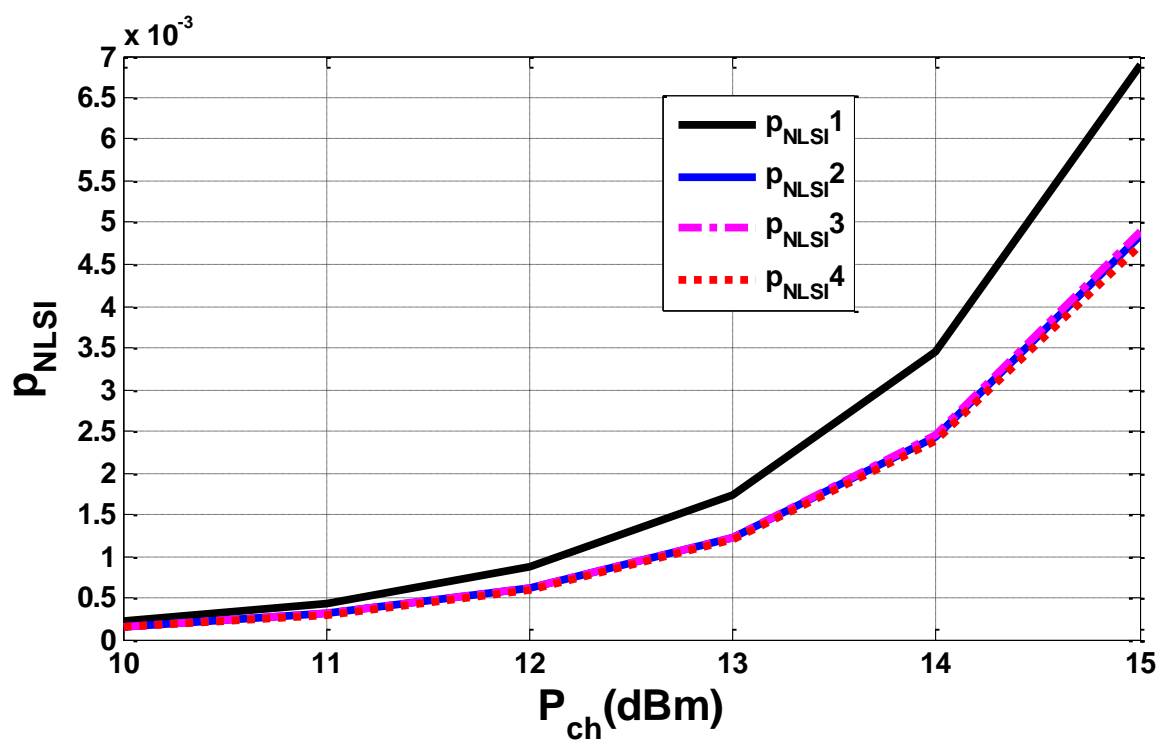

Fig. 2 (b): Non-linear signal interference for four GN models considering power of nonlinear signal interference $\left(p_{N L S I}\right)$ vs. channel power $\left(\mathrm{P}_{\mathrm{ch}}\right)$ with SF.

Fig.2 (a) represents the power of nonlinear signal inference versus line rate of the COTS. This result is simulated for SF with 27 channels, $32 \mathrm{GHz}$ channel bandwidth $\left(\mathrm{B}_{\mathrm{ch}}\right), 50 \mathrm{GHz}$ channel spacing $(\Delta f)$, center frequency $\left(f_{c}\right) 193.4145 \mathrm{THz}$, channel power $\left(P_{c h}\right) 10 \mathrm{dBm}$, number of span $\left(\mathrm{N}_{\mathrm{s}}\right)$ is 1 , span length $\left(\mathrm{L}_{\mathrm{s}}\right) 100 \mathrm{~km}$, optical noise bandwidth $\left(\mathrm{B}_{\mathrm{n}}\right) 12.5 \mathrm{GHz}$. In this figure, Black, Blue, Magenta and Red lines carry the information for $p_{N L S I^{1}}, p_{N L S I^{2}}, p_{N L S I^{3}}$ and $p_{N L S I^{4}}$ respectively. It is found that the power of nonlinear interference is going down with the increment values of $\mathrm{R}_{\mathrm{s}}$. Magenta and Blue lines are fitted very well. Magenta, Blue and Red lines are seemed to be very closed for line rate from $0.028 \mathrm{THz}$ to $0.032 \mathrm{THz}$. On the other hand, Black line shows very small nonlinear signal inference in comparison with Blue and Magenta lines. It is found that Blue line shows very good accuracy compared to other three models. 
Fig.2 (b) is simulated for channel power $\left(\mathrm{P}_{\mathrm{ch}}\right)$ and power of nonlinear signal interference ( $\mathrm{p}_{\mathrm{NLSI}}$ ) based on all parameters used in Fig.2 (a).In this results, Black, Blue, Magenta and Red lines are used for $p_{N L S I^{1}}, p_{N L S I^{2}}$, $p_{N L S I^{3} \text { and }} p_{N L S I^{4}}$ respectively. The nonlinear signal interference power is going up with the increase of channel power in the system. It is found that Blue, Magenta and Red lines show the best fitting curve for channel power $10 \mathrm{dBm}$ to $15 \mathrm{dBm}$. The Black line performs the good matching for $10 \mathrm{dBm}$ to $11 \mathrm{dBm}$ channel power. It is selected that the Blue line performs the good accuracy. The optimum OSNR [7] [18] depends on span transmitting input power $\left(P_{T X}\right), P_{A S E}$ and $p_{N L S I^{2}}$ as expressed below:

$$
\begin{gathered}
P_{A S E}=A_{S} F h f_{o} B_{n} \\
\text { OSNR }=\frac{P_{T X}}{N_{S}\left(P_{A S E}+P_{T X}^{3} p_{N L S{ }^{2}} B_{\mathrm{ch}}^{-3}\right)}
\end{gathered}
$$

In Equ.(11) $A_{S}, F, h$ and $f_{o}$ are the span loss, noise figure, plank constant and center frequency of the channel of comb respectively. In this simulation we put noise figure $5 \mathrm{~dB}$, where span loss depends on span length and fiber loss coefficient per kilometer of SF. In Equ. (12), $N_{S}$ is the number of spans. It is used 50 spans in our simulation process.

To measure the Bit Error Rate (BER), OSNR is required where OSNR determined from $p_{N L S I^{2}}, P_{A S E}$ and $P_{T X}$ respectively. For PM-16QAM modulation format, 16 GBaud and $32 \mathrm{GBaud}$ produced $128 \mathrm{~Gb} / \mathrm{s}$ and $256 \mathrm{~Gb} / \mathrm{s}$ line bit rates respectively.

SNR is required to determine the BER. SNR is related with OSNR and BER is expressed below [9].

$$
S N R=\left(\frac{B_{n}}{R_{s}}\right) O S N R
$$

$\mathrm{BER}=\phi(S N R)$

$\phi$ is the modulation format that operates the bit rates and upgrade the system. The modulation format for PM16QAM used in [9]

$$
\mathrm{BER}_{(\mathrm{PM}-16 \mathrm{QAM})}=\frac{3}{8} \operatorname{erfc}\left(\sqrt{\frac{1}{10} S N R}\right)
$$

In Equ. (15) erfc is the complementary error function.

\section{Optimization Of OSNR For COTS}

Based on theoretical analysis, the simulation is done with SF commercial optical fiber. This result is with 27 channels, $32 \mathrm{GHz}$ channel bandwidth $\left(\mathrm{B}_{\mathrm{ch}}\right), 50 \mathrm{GHz}$ channel spacing $(\Delta \mathrm{f})$, center frequency $\left(\mathrm{f}_{\mathrm{c}}\right) 193.4145$ [THz], channel power $\left(\mathrm{P}_{\mathrm{ch}}\right) 15 \mathrm{dBm}$, number of $\operatorname{span}\left(\mathrm{N}_{\mathrm{s}}\right)$ is 50 , span length $\left(\mathrm{L}_{\mathrm{s}}\right) 100 \mathrm{~km}$, optical noise bandwidth $\left(\mathrm{B}_{\mathrm{n}}\right) 12.5 \mathrm{GHz}$.

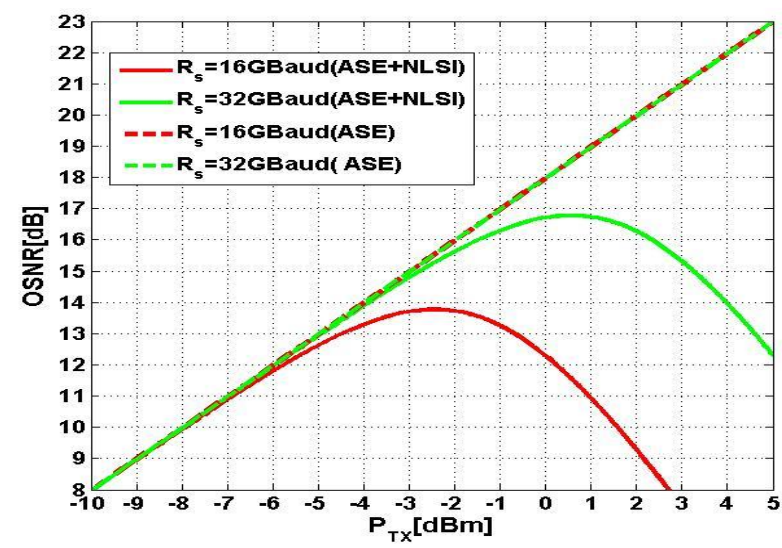

Fig.3. (a): OSNR [dB] versus $\mathrm{P}_{\mathrm{TX}}[\mathrm{dBm}]$ based on linear and nonlinear propagation considering 16GBaud and $32 \mathrm{GBaud}$ line rates of the COTS of SF 


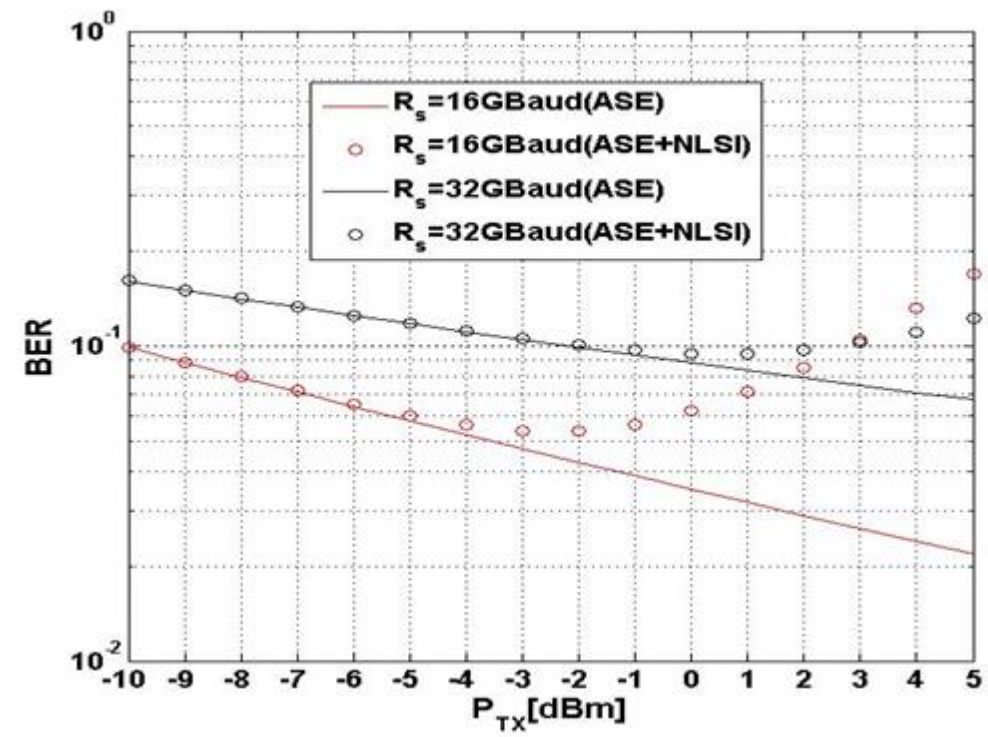

Fig.3. (b): $\mathrm{P}_{\mathrm{TX}}[\mathrm{dBm}]$ versus $\mathrm{BER}$ based on linear and nonlinear propagation considering $16 \mathrm{GBaud}$ and $32 \mathrm{GBaud}$ line rates of the COTS of SF

In Fig.3 (a) OSNR [dB] versus $P_{T X}[\mathrm{dBm}]$ where dotted lines represent the linear propagation; solid lines show the non-linear propagation. Blue line is for $16 \mathrm{Gbaud}$ and Red line is for $32 \mathrm{GBaud}$ line rates. Case for nonlinear signal propagation, the optimum OSNR is $13.77 \mathrm{~dB}$ and $16.78 \mathrm{~dB}$ when $P_{T X}$ is $-2.44 \mathrm{dBm}$ and $0.5 \mathrm{dBm}$ considering 16GBaud and 32GBaud respectively. For the result's confirmation, it is found that the optimum penalty between linear and nonlinear propagation is around $1.76 \mathrm{~dB}$ [21]. It is also confirmed that the lines overlap for 16GBaud and 32GBaud respectively considering linear propagation. It is also found that OSNR changed corresponding to the $P_{T X} \mathrm{dBm}$ by $1 \mathrm{~dB}$ linearly. For the same modulation format, the optimum OSNR difference is $3 \mathrm{~dB}$ following the factor of $2 x$ bit rate and $4 x$ bit rate. Fig. 3(b) is the plot of BER for PM-16QAM modulation format. In this case it is assumed that all parameters used here is the same as used previously for Fig.3 (a).

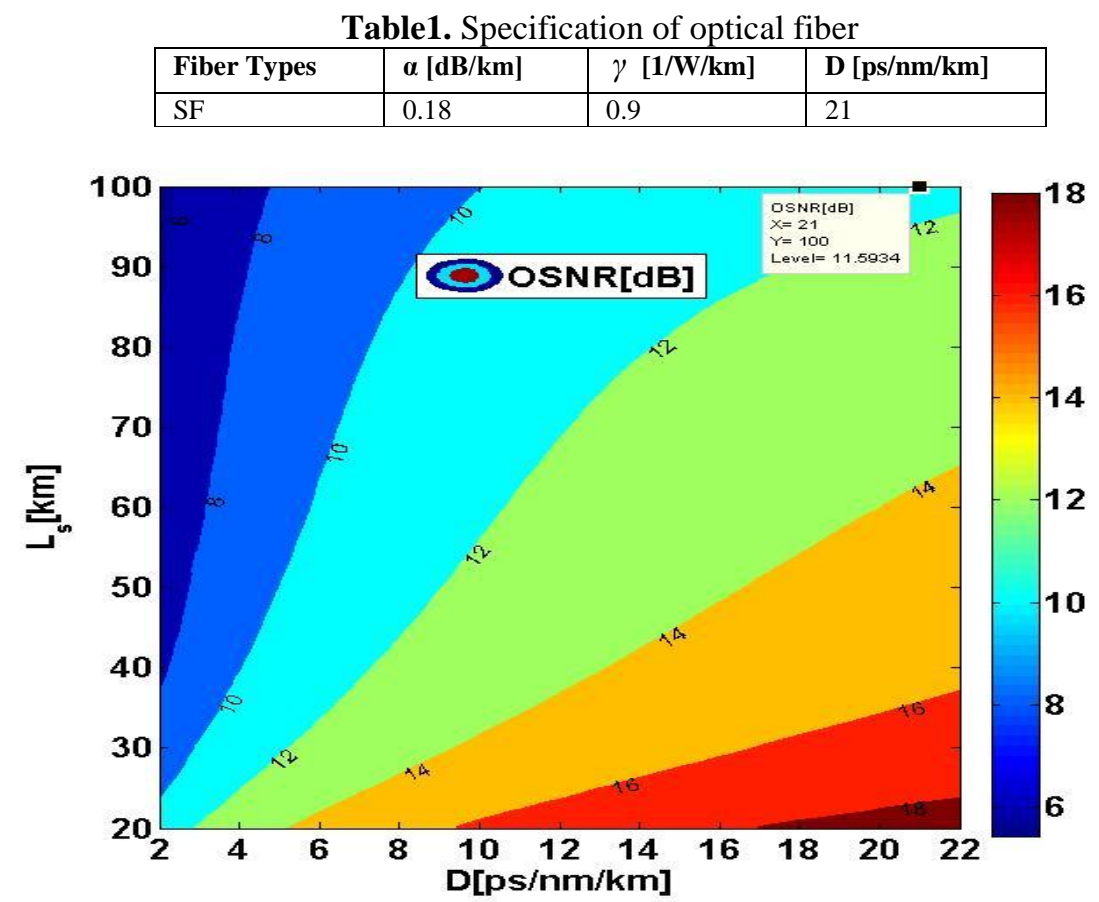

Fig.4. (a): Considering line rate 16GBaud, contour plot of OSNR versus span length $[\mathrm{km}]$ and dispersion $[\mathrm{ps} / \mathrm{nm} / \mathrm{km}]$ parameter of SF. 


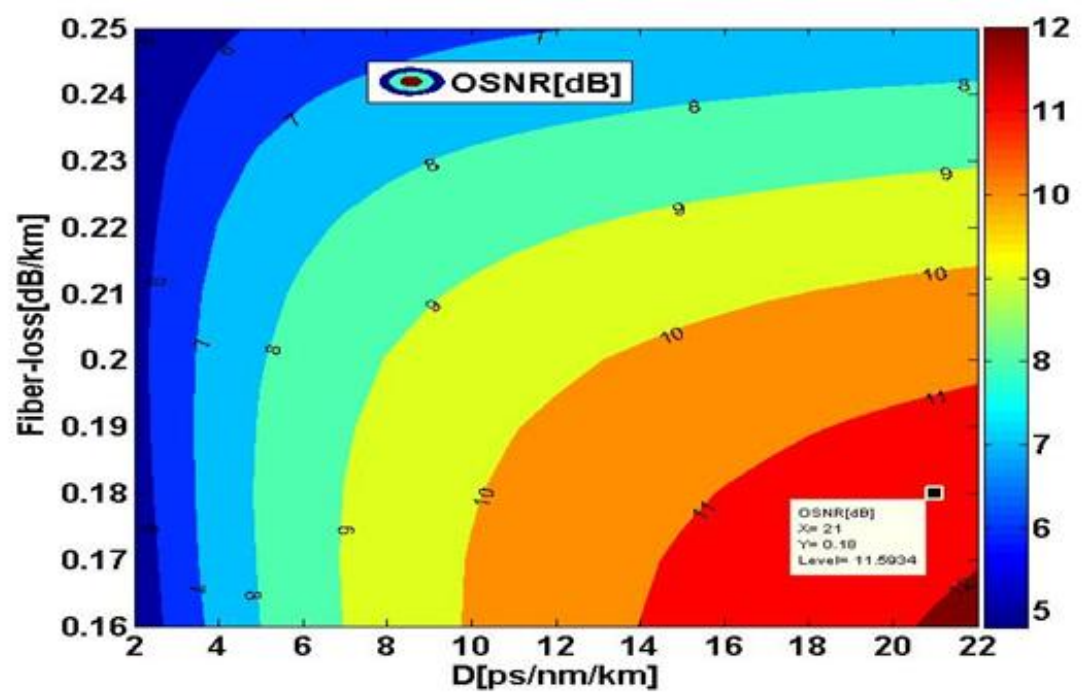

Fig. 4(b): allowing for line rate 16GBaud, contour plot of OSNR [dB] versus fibre loss [dB/km] and dispersion $[\mathrm{ps} / \mathrm{nm} / \mathrm{km}]$ parameter of SF

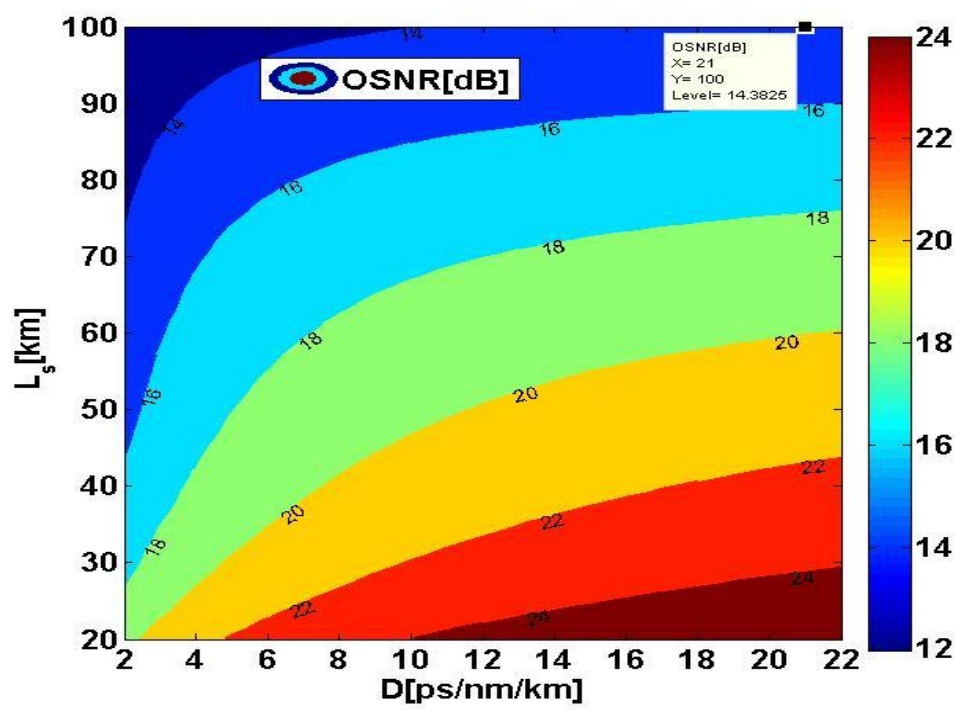

Fig. 4. (c): Considering line rate $32 \mathrm{GBaud}$, contour plot of OSNR $[\mathrm{dB}]$ versus span length $[\mathrm{km}]$ and dispersion $[\mathrm{ps} / \mathrm{nm} / \mathrm{km}]$ parameter of $\mathrm{SF}$

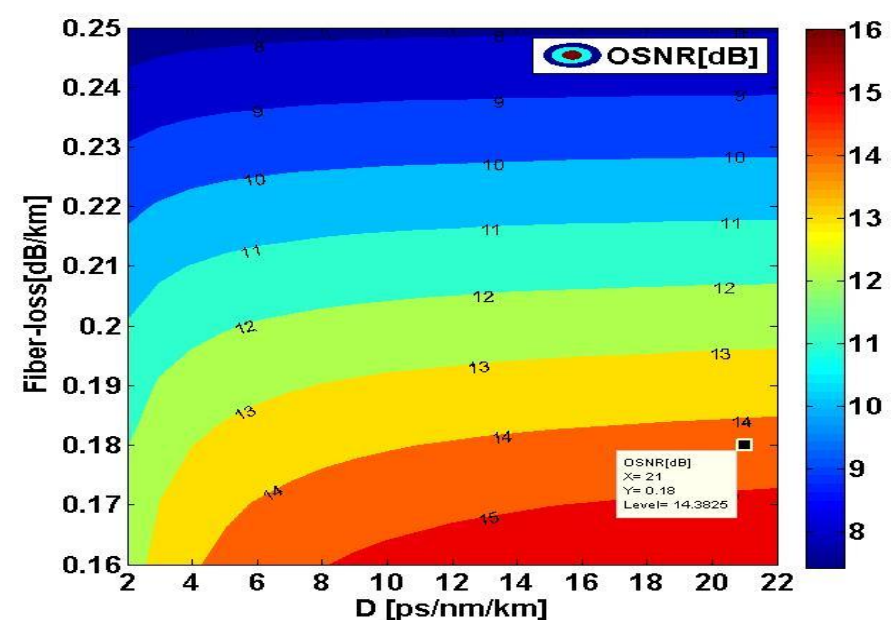

Fig. 4(d): Considering line rate 32GBaud, contour plot of OSNR [dB] versus fibre loss coefficient $[\mathrm{dB} / \mathrm{km}]$ and dispersion $[\mathrm{ps} / \mathrm{nm} / \mathrm{km}]$ parameter for $\mathrm{SF}$ 
Fig.4 (a) is the contour plot of OSNR versus span length $[\mathrm{km}]$ and dispersion $[\mathrm{ps} / \mathrm{nm} / \mathrm{km}]$ parameter of SF. Fig.4 (b) shows contour plot of OSNR $[\mathrm{dB}]$ versus fibre loss coefficient $[\mathrm{dB} / \mathrm{km}]$ and dispersion parameter $[\mathrm{ps} / \mathrm{nm} / \mathrm{km}]$ of SF. Both plots are for $16 \mathrm{GBaud}$ and 50 numbers of spans. with 27 channels, $32 \mathrm{GHz}$ channel bandwidth $\left(\mathrm{B}_{\mathrm{ch}}\right), 50 \mathrm{GHz}$ channel spacing $(\Delta f)$, center frequency $\left(f_{c}\right) 193.4145 \mathrm{THz}$, channel power $\left(P_{c h}\right) 10 \mathrm{dBm}$, span length $\left(\mathrm{L}_{\mathrm{s}}\right) 100 \mathrm{~km}$, optical noise bandwidth $\left(\mathrm{B}_{\mathrm{n}}\right)$ 12.5GHz. It is found that the optimum OSNR is $11.59 \mathrm{~dB}$ for Fig.4 (a) and Fig.4 (b) when dispersion $21[\mathrm{ps} / \mathrm{nm} / \mathrm{km}$ ], span length $100 \mathrm{~km}$ and fibre loss coefficient $0.18[\mathrm{~dB} / \mathrm{km}]$. On the other hand Fig.4(c) and Fig.4 (d) are the contour plot of OSNR versus span length $[\mathrm{km}]$ and dispersion $[\mathrm{ps} / \mathrm{nm} / \mathrm{km}$ ] parameter, OSNR $[\mathrm{dB}]$ versus fibre $10 \mathrm{ss}[\mathrm{dB} / \mathrm{km}]$ and dispersion $[\mathrm{ps} / \mathrm{nm} / \mathrm{km}]$ parameter of SF considering $32 \mathrm{GBaud}$. Here, it is found that the optimum OSNR is $14.38 \mathrm{~dB}$ when dispersion $21[\mathrm{ps} / \mathrm{nm} / \mathrm{km}]$, span length $100 \mathrm{~km}$ and fibre loss coefficient $0.18[\mathrm{~dB} / \mathrm{km}]$. The OSNR penalty between $16 \mathrm{Gbaud}$ and $32 \mathrm{GBaud}$ is $2.8 \mathrm{~dB}$ when $P_{T X}=-10 \mathrm{dBm}$ to- $3 \mathrm{dBm}$.

\section{Conclusion}

In conclusion, this paper describes a detailed evaluation on four GN models successfully. These four GN models, $p_{N L S I^{2}}$ is the most fitted with better accuracy than the other models considering same symbol rate and channel power. When the channel power $\left(\mathrm{P}_{\mathrm{ch}}\right) 15 \mathrm{dBm}$ is considered for $128 \mathrm{~Gb} / \mathrm{s}$ and $256 \mathrm{~Gb} / \mathrm{s}$ data rates, the optimum OSNR is $13.77 \mathrm{~dB}$ and $16.78 \mathrm{~dB}$ when $P_{T X}=-2.44 \mathrm{dBm}$ and $0.5 \mathrm{dBm}$ respectively. Considering channel power (Pch) of $10 \mathrm{dBm}$, the optimum OSNR is $11.59 \mathrm{~dB}$ and $14.38 \mathrm{~dB}$ for a dispersion parameter (D) of $21[\mathrm{ps} / \mathrm{nm} / \mathrm{km}]$, fiber loss coefficient $(\boldsymbol{\alpha}) 0.18[\mathrm{~dB} / \mathrm{km}]$ and span length $(\mathrm{Ls}) 100 \mathrm{~km}$. For the same transmission format it is found that, the OSNR variation is the factor of around $3 \mathrm{~dB}$ and $6 \mathrm{~dB}$ with respect to the $2 x b i t$ rate and $4 \mathrm{xbit}$ rate respectively.

\section{References}

[1] John D. Downie, "112 Gb/s PM-QPSK transmission systems with reach lengths enabled by optical fibers with ultra-low loss and very large effective area," 2012 Photonics West Conference, pp. paper 828403, January 2012

[2] V. Bobrovs, A. Udalcovs, R. Parts, and I. Trifonovs, "Evaluation of Nonlinear Effect Impact on Optical Signal Transmission over Combined WDM System," PIERS Proceedings, Taipei, Mar. 2013.

[3] N. B. Pavlovic and R. Nogueira, "Optimization of Extreme Optical Links for Network Upgrades," ICTON 2012.

[4] Eduardo S. Rosa1,Victor E. S. Parahyba1, Júlio C. M. Diniz, Vitor B. Ribeiro1 and Júlio C. R. F.Oliveira, "Nonlinear Effects Compensation in Optical Coherent PDM-QPSK Systems," Journal of Microwaves, Optoelectronics and Electromagnetic Applications, Vol. 12, No. 2, December 2013.

[5] Pontus Johannisson and Erik Agrell, "Modeling of Nonlinear Signal Distortion in Fiber-Optical Networks", posted on arXiv, www.arxiv.org, paper identifier: 1309.4000v1, 16 sep. 2013.

[6] Kerry Hinton, J. C. Li,Peter M. Farrel, Wayne V. Sorin, “A New Design Technique for Optical Links”, WU1, 15.30 - 15.45, 2009.

[7] Pierluigi Poggiolini, "The GN Model of Non-Linear Propagation in Uncompensated Coherent Optical Systems," J. Lightw. Technol., vol. 30, no.24, Dec. 2012.

[8] P. Poggiolini, A. Carena, V. Curri, G. Bosco, and F. Forghieri, "Analytical modeling of nonlinear propagation in uncompensated optical transmission links," IEEE Photon. Technol. Lett., vol. 23, no. 11, pp. 742-744, Jun. 2011.

[9] A. Carena, V. Curri, G. Bosco, P. Poggiolini, and F. Forghieri, "Modeling of the impact of nonlinear propagation effects in uncompensated optical coherent transmission links," J. Lightw. Technol., vol. 30, no. 10, pp. 1524-1539, May 2012.

[10] Pierluigi Poggiolini, Gabriella Bosco, Andrea Carena, Vittorio Curri, Yanchao Jiang and Fabrizio Forghieri, "A Detailed Analytical Derivation of the GN Model of Non-Linear Interference in Coherent Optical Transmission Systems", posted on arXiv, www.arxiv.org, paper identifier :1209.0394, (2012).

[11] A. Nespola, S. Straullu, A. Carena, G. Bosco, R. Cigliutti, V. Curri, P. Poggiolini, M. Hirano, Y. Yamamoto, T. Sasaki, J. Bauwelinck, K. Verheyen, F. Forghieri, "Extensive Fiber Comparison and GN-model Validation in Uncompensated Links using DAC-generated Nyquist-WDM PM-16QAM Channels," Opt. Fiber Commun. Conf. (OFC/NFOEC) Technical Digest, OSA, 2013.

[12] Vittorio Curri, Pierluigi Poggiolini, Gabriella Bosco, Andrea Carena, and Fabrizio Forghieri, "Performance Evaluation of LongHaul 111 Gb/s PM-QPSK Transmission Over Different Fiber Types,” IEEE Photon. Technol. Lett., vol. 22, no. 19, Oct. 2010.

[13] www.MapYourTech.com,“COMBATING OSNR IN DWDM LINKS,” a power point presentation; http://www. slideshare. net/sanmap/techniques-to-combat-osnr-in-dwdm-links

[14] A. Carena, G. Bosco, V. Curri, P. Poggiolini, F. Forghieri, "Impact of the Transmitted Signal Initial Dispersion Transient on the Accuracy of the GN-Model of Non-Linear Propagation”, Eur. Conf. Opt. Commun. (ECOC), paper Th.1.D.4, 2013.

[15] P. Poggiolini, G. Bosco, A. Carena, R. Cigliutti, V. Curri, F. Forghieri, R. Pastorelli, S. Piciaccia, "The LOGON Strategy for LowComplexity Control Plane Implementation in New-Generation Flexible Networks," Opt. Fiber Commun. Conf. (OFC/NFOEC), OSA,2013.

[16] Abdul Gafur, Md. Razu Ahmed, Md. Badiuzzaman and Abu Riduan Md Foisal, "OSNR Improvement of Coherent Uncompensated Optical Transmission Systems for Various Commercial Optical Fiber Types," ICEEICT Proceedings, 10-12 April, 2014, Dhaka, Bangladesh.

[17] G. Bosco, A. Carena, R. Cigliutti, V. Curri, P. Poggiolini, “ Next generation Terabit Optical networks: theory, simulation and experiments,” Poster-session, DET-day, http://www.det.polito.it/focus/det_day/session_1_14_15_15_00.

[18] Vittorio Curri, Andrea Carena, Pierluigi Poggiolini, Gabriella Bosco, and Fabrizio Forghieri, "Extension and validation of the GN model for non-linear interference to uncompensated links using Raman amplification,” Optical Express, Vol. 21, No. 3,11, February 2013.

[19] Robert Maher, Tianhua Xu, Lidia Galdino, Masaki Sato, Alex Alvarado, Kai Shi, Seb J. Savory, Benn C. Thomsen, "Spectrally Shaped DP16QAM SuperChannel Transmission with MultiChannel Digital BackPropagation," Scientific Reports 5, Nature Publishing Group, Article number: 8214 doi:10.1038/srep08214, Feb. 2015.

[20] P. Poggiolini, G. Bosco, A. Carena, V. Curri, F. Forghieri, "The GN-Model of Fiber Non-Linear Propagation and its Applications," J. Lightw. Technol., vol. 32, no. 4, pp. 694-721, April 2014.

[21] G. Bosco, A. Carena, R. Cigliutti, V. Curri, P. Poggiolini, F. Forghieri, "Performance Prediction for WDM PM-QPSK Transmission over Uncompensated Links", in Proc. of OFC 2011, Los Angeles (USA), paper OThO7, Mar. 2011. 